\title{
Opinions of traditional birth attendants in Ibadan, Nigeria, towards reversal of eruption sequence of primary central incisors in infants
}

\author{
Olubunmi Olusola Bankole ${ }^{1 *}$, Juliana Obontu Taiwo ${ }^{2}$, Adeyemi Isaiah Falegan $^{3}$ \\ ${ }^{1}$ Department of Child Oral Health, College of Medicine, University of Ibadan, Ibadan, Nigeria; \\ *Corresponding Author: bumbank2002@yahoo.com \\ ${ }^{2}$ Department of Community Dentistry and Periodontology, University of Ibadan, Ibadan, Nigeria \\ ${ }^{3}$ Department of Community Dentistry and Periodontology, University College Hospital, Ibadan, Nigeria
}

Received 22 May 2013; revised 23 June 2013; accepted 15 July 2013

Copyright (C) 2013 Olubunmi Olusola Bankole et al. This is an open access article distributed under the Creative Commons Attribution License, which permits unrestricted use, distribution, and reproduction in any medium, provided the original work is properly cited.

\section{ABSTRACT}

Introduction: Traditional birth attendants (TBA's) have been a good medium for transferring health education messages in culturally acceptable ways. It is believed that they will be a good asset to demystify the misconceptions associated with reversal of eruption sequence in the community. Aim: To assess the opinions of TBA's towards reversal of eruption sequence of primary central incisors in infants. Methods: A cross sectional study was conducted among all consenting TBA's in the five urban local government areas in Ibadan, using a pretested 17-item semi structured interviewer administered questionnaire. Results: Forty eight $(29.4 \%)$ respondents will be astonished at seeing children erupting upper primary central incisors before the lowers, while $25(15.3 \%)$ will regard them as strange. Thirty five $(21.1 \%)$ respondents felt this condition was due to evil spirits while $13(8.0 \%)$ believed that child's parents had breached traditional taboos. There was a correlation between negative beliefs about this variation and age $(p=0.038)$ and education $(p=0.020)$. Their opinion on the families of the affected children was hideous as (13.5\%), (23.3\%) and (27.6\%) regarded it as a curse, embarrassment and abomination respectively and this was associated with their educational status $(p=0.014)$. Many $(61.3 \%)$ of the respondents would advise the parents to hide or get rid of such children whilst (33.7\%) advocated for extraction and only 8 (4.9\%) felt child and the tooth should be left alone. Conclusion: Many of the TBA's have dissenting mind-sets towards such children and their families. The practices of many of the TBA's towards such teeth are disturbing and necessitate urgent intervention. The risks are that wrong advice may be given to such parents by the TBA's and affected children may be deserted, abandoned, stigmatized and exposed to hazards. Older and less educated TBA's have a greater tendency to believe these misconceptions.

Keywords: Eruption Sequence; Infants; Opinions; Primary Central Incisors; Traditional Birth Attendants

\section{INTRODUCTION}

Many parents are anxious about the timing of eruption of their babies teeth which is considered as an important milestone during a child's development [1]. Invariably it is expected that the mandibular central incisor will be the first tooth to erupt as it is the case with majority of children [2-5]. However, the maxillary primary incisors have sometimes erupted before the mandibular ones [6]. Records of prevalence rates of reversal of eruption sequence of primary central incisors in infants appear scarce even though reports of isolated cases exist in literature [6,7].

This unusual occurrence is not acceptable in some parts of Nigeria particularly among the Yoruba tribes because it is often viewed as a bad omen for the child and the family [6]. Parents have brought such babies to the dental clinic requesting the extraction of the maxillary 
central incisors which have erupted ahead of the mandibular central incisors [7]. From the personal observation by the authors, even though the affected parents are usually reassured and sent home, it has resulted in some parents employing alternate traditional means to get these teeth forcefully extracted due to the fear of being ridiculed in the community.

In the developing world traditional birth attendants (TBA's) also known as traditional midwives, have played a major role in antenatal and post natal care of women in the community [8]. Research shows that in Nigeria, about $70 \%$ of all deliveries are attended to by the TBA's [9]. Traditional birth attendants are highly regarded in their communities [10] and are very influential. Studies have demonstrated that they are good mediums for transferring health education messages as they convey messages in a way the community recognizes and accepts [11]. It is the opinion of the authors that the TBA's will be a good asset to demystify the misconceptions associated with reversal of eruption sequence in the community.

However, in order to achieve this, it is important to find out the background attitude and knowledge of TBA's about reversal of eruption sequence of primary central incisors in infants.

There seems to be no information in literature on the attitude and beliefs of TBA's to reversal of eruption sequence of primary central incisors in Nigeria.

The aim of this study thus, was to assess the opinions of TBA's reversal of eruption sequence of primary central incisors in children.

\section{METHODS}

The study was conducted on one hundred and sixty three consenting TBA's in Ibadan, Nigeria. Ibadan is located in the South western part of Nigeria with a population of over 2.5 million [12]. Traditional birth attendants in Ibadan urban local government areas namely Ibadan North, North West, South West, South East and North East Local Governments Areas participated in the study.

A list of registered TBA's in the various urban Local Government Areas was collected from the Oyo State Ministry of Health [13]. Inclusion criteria consisted of all Traditional birth attendants registered with the Ministry of Health in the five urban local government areas. Exclusion criteria included Traditional birth attendants who were unwilling to participate in the study. All consenting TBA's in the five urban Local Government Areas in Ibadan participated in the study.

The study instrument consisted of a semi structured, seventeen item questionnaire designed and translated into the local Yoruba language which was pretested among ten TBA's who were not among the study popu- lation. The questionnaire was divided into four parts.

1) Basic demographic data (6 questions).

2) Knowledge about the eruption sequence (6 question).

3) Attitudes towards affected child and family (3 questions).

4) Practices of the TBA's regarding this condition (2 questions).

Data collection was done during the monthly meeting of the TBA's in their various local governments. The questionnaires were administered by four trained research assistants.

Permission was obtained from of the Local Government Authorities and informed consent was taken from the respondents before the start of the study. The study was carried out in strict compliance with Helsinki Declaration principle of studies involving human subjects

Data entry and analysis was done using the software SPSS version 15. Frequency distributions were generated. Chi square test was used to test significance of categorical variables. Associations were considered significant when p-values were equal or less than 0.05 .

\section{Ethics Approval: Committee Which Approved Research}

Ethical Review Committee, Ministry of Health, Oyo State of Nigeria.

\section{RESULTS}

The participants consisted of 163 TBA's mainly from the Yoruba ethnic group (96.3\%). Three respondents each (1.8\%), were from the Igbo and Hausas tribes. Majority of TBA's, 156 (95.7\%) were females and participants ages ranged between 25 and 75years. The mean age was 47 years ( $\mathrm{SD}=10.82$ years). Thirty seven TBA's (22.7\%) were less than 40 years while almost half (47.9\%) were above 50 years of age. Religious distribution showed that 124 (76.1\%) were Christians and 39 (23.9\%) were Muslims. Among the participants, eighty (49.1\%) respondents had secondary education, 40 (24.5\%) had primary school education while 27 (16.6\%) were illiterates. Seventy five TBA's (46\%) had been practicing for less than 10 years while 31 (19\%) had more than 20 years professional experience.

Ninety seven (59.5\%) of the TBAs had attended to children with the lower primary central incisors erupting before the uppers. It was a unanimous opinion among them that the mandibular primary central incisors should erupt ahead of the uppers.

Forty eight (29.4\%) respondents will be astonished at seeing them, while 25 (15.3\%) will regard such children as strange (Figure 1).

Thirty five (21.1\%) respondents felt this condition was 


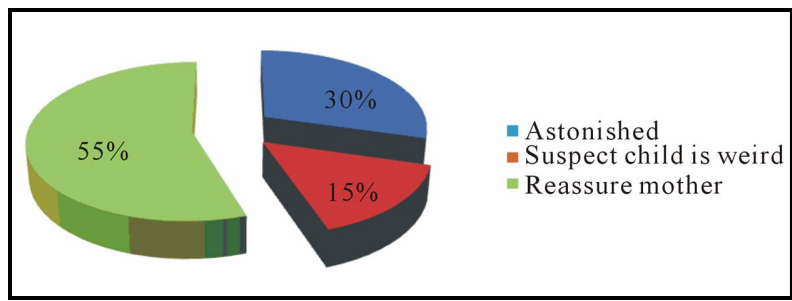

Figure 1. TBA's attitude to reversal of eruption sequence of primary central incisors in infants. due to evil spirits while $13(8.0 \%)$ believed child's parents had breached traditional taboos (Table 1). There was a correlation between negative beliefs about this variation and age and education .Majority of TBA's over 50 years of age in comparison to the younger ones believed this reversal of eruption sequence was caused by evil spirits ( $p=0.038$ ) (Figure 2). Respondents with no or primary education in contrast to those with higher education also believed this reversal sequence was due to

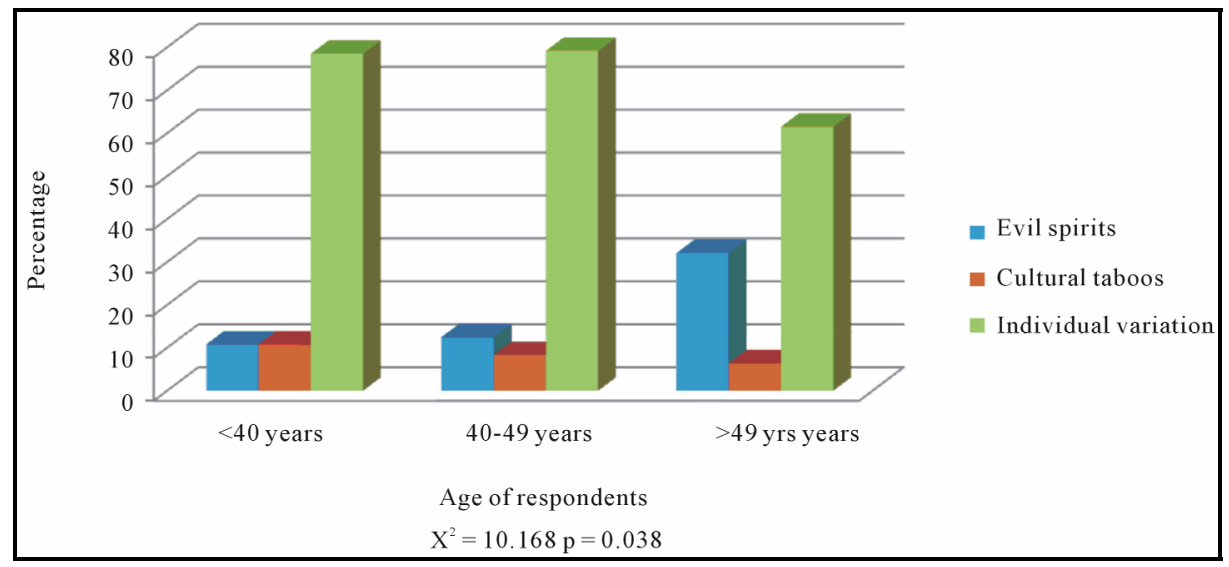

Figure 2. Influence of TBA's age on the perieved causes of eruption sequence of primary central incisors in infants.

Table 1. Frequency distribution of beliefs and practices of the TBA's towards reversal of eruption sequence of primary central incisorsin infants.

Perceived causes of eruption of upper primary central incisors before lowers

$\mathrm{N}$

Parents breached traditional taboos

Get tooth extracted (with/without sacrifices)
Evil spirits

Individual variation

Effect on child's family

Cursed family

Embarrassment

Abomination

No effect

Advice to family

Hide/get rid of child

Leave child alone

35

13

115

22

38

45

58

100

55

8

Advice to forestall occurrence
$\%$

8.0

70.5

13.5

23.3

27.6

35.6

61.3

33.7

4.9

15

9.2

48

29.5

Avoid breaking traditional cultural laws

100

61.3 


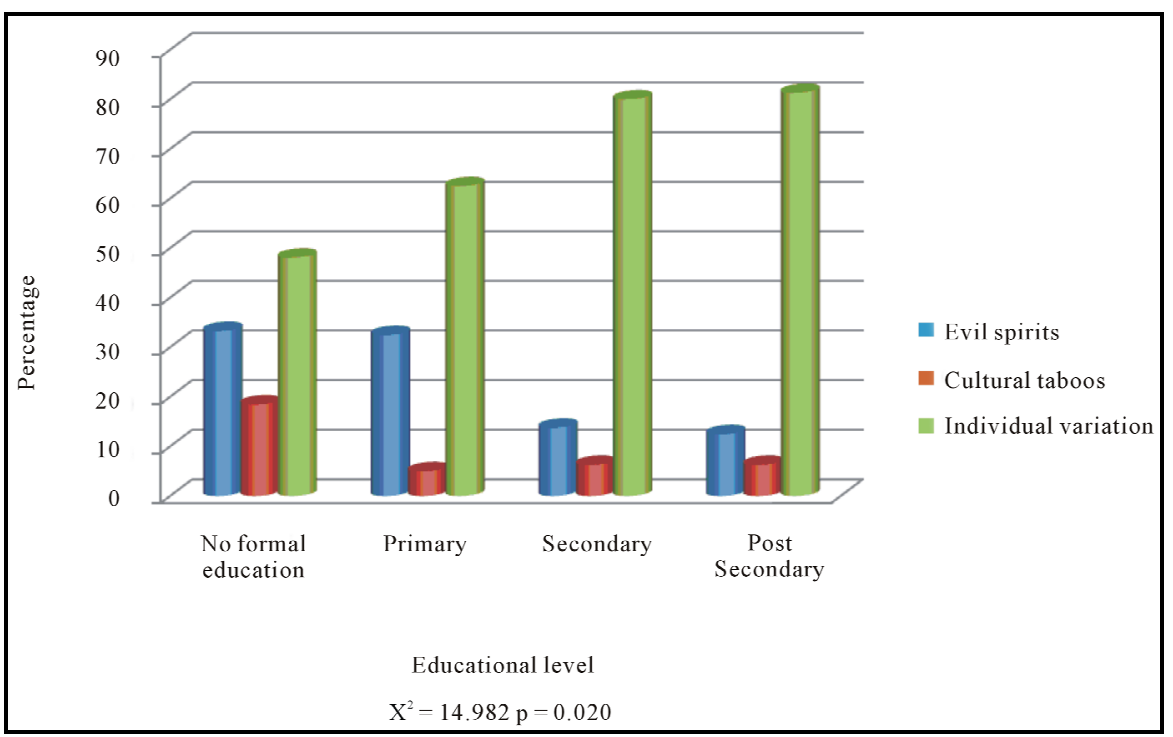

Figure 3. The influence of TBA's educational status on the perceived causes of reversal of eruption sequence of primary central incisors in infants.

evil spirits $(\mathrm{p}=0.020)$ (Figure 3).

Their opinion on the families of the affected children was hideous as (13.5\%), (23.3\%) and (27.6\%) regarded it as a curse, embarrassment and abomination respectively (Table 1) and this was highly associated with their educational status $(\mathrm{p}=0.014)$ (Figure 4).

Many (61.3\%) of the respondents would advise the parents to hide or get rid of such children whilst (33.3\%) advocated for extraction and only 8 (4.9\%) felt child and the tooth be left alone (Table 1). There was a tendency for the older respondents above 50 years in comparison to the younger to advice immediate extraction of teeth, even though it was not statistically significant $(\mathrm{p}=$ 0.207).

Over a third (38.7\%) of the TBA's felt this condition is preventable. In line with this, slightly less than a tenth (9.2\%) advised regular intake of traditional concoctions by pregnant women while over a quarter (29.5\%) were of the opinion that pregnant women must avoid contravening taboos and should respect traditional cultural principles (Table 1).

It was considered by (22.7\%), (41.7\%), (2.5\%) of the TBA's respectively that odd behavior, possession of evil spiritual powers and child being dull academically were consequences of this reversal of eruption sequence (Figure 5).

\section{DISCUSSION}

In Africa, especially in Nigeria societal myths have led to unpleasant social experiences. The killing of twins children in Calabar, Nigeria is one of the effects of such myths [14]. Likewise in the Yoruba region of south western Nigeria, reversal sequence of eruption of primary incisors in infants has led to objectionable circumstances for them as they are derogatorily referred to as as "omo eleyinoke" ("children with upper teeth") in the society. Consequently they are often looked down on, harassed and stigmatized.

African ethnographies also occasionally report that infants whose upper teeth erupt before their lower teeth have been killed because of such "developmental anomalies" [15]. Among the Baribas in Benin republic such a condition has been regarded as a criterion for determining if a child is a witch [16]. Furthermore, among some members of the Hamer tribe in southwestern Ethiopia [17], Igbo in Nigeria [18], Marakwet of Kenya [19], Indians [20] and Punjabis [21] such children have been considered a bad omen and sign of misfortune.

This study has demonstrated that TBA's have wrong beliefs and attitudes towards reversal of eruption sequence of deciduous incisor teeth. This needs to be viewed gravely since TBA's play an important role in the Yoruba community. Despite the fact that more than half have attended to such children they still have the misconception that these children are weird. This is in consonance with the study by Aderinokun and Oyejide (1991) [6], in which $70.4 \%$ of Yoruba rural dwellers in two villages in southwestern Nigeria regarded the eruption of upper primary incisors before the lowers to be a sign of an evil child.

Many TBA's attribute the causes of such conditions to evil spirits and as such wrong advice which could be hazardous may be given to mothers in managing the condition. Some of the TBA's advised that pregnant women should have regular intakes of traditional concoctions to forestall such happenings. Many of these concoctions in Nigeria are not scientifically proven and doses are not 


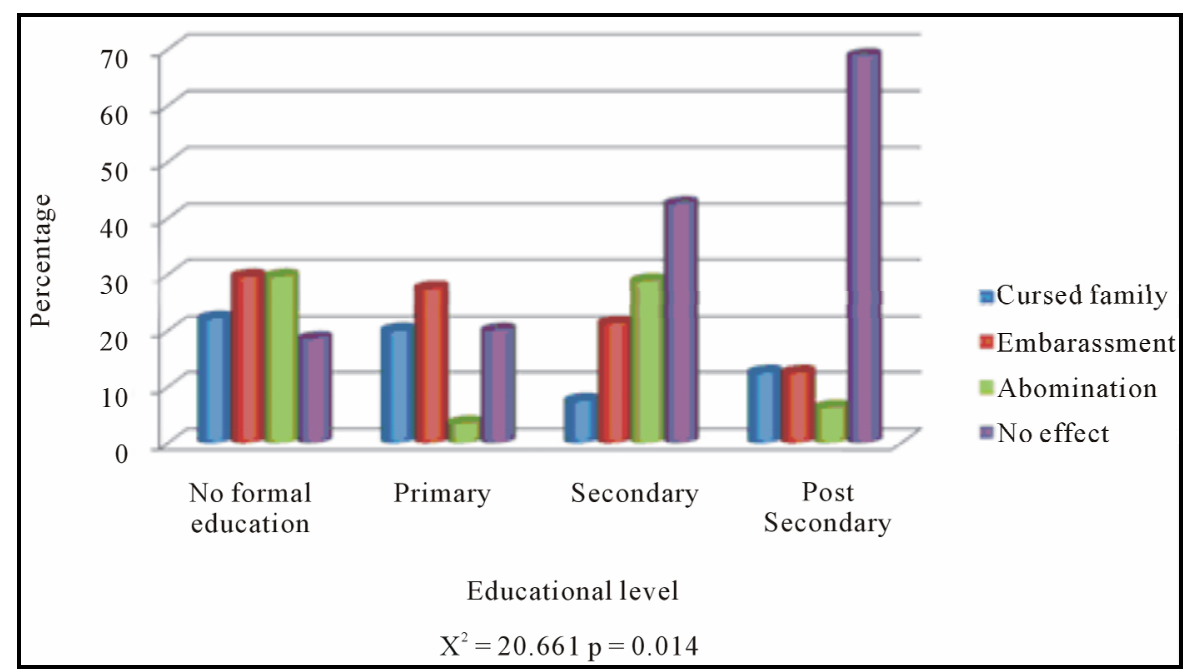

Figure 4. The influence of TBA'S educational status on effect of reversal of eruption sequence in primary central incisors on the child's family.

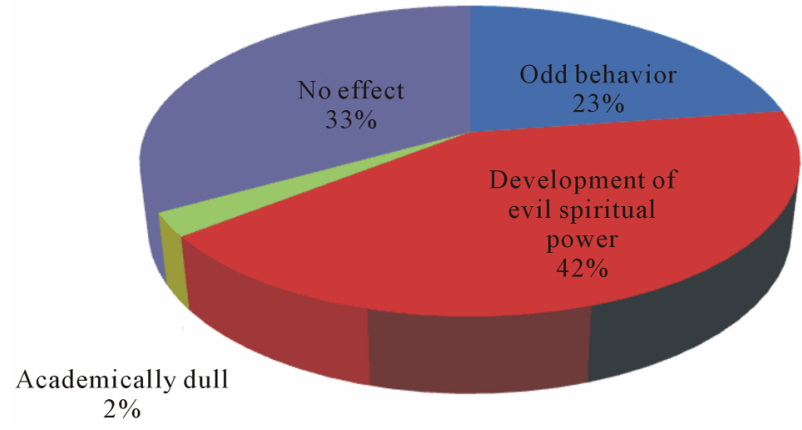

Figure 5. TBA's views on the effect of reversal of eruption sequence of primary central incisors on the child in the future.

regulated or ascertained [22]. This could mean be an increased risk to the health of the mother or even the unborn child. Their beliefs will also have psychological consequences on these children and their families as majority the TBA's will advise the family to hide or get rid of the child. This practice may not be unconnected with the fact that they believed that bizarre behavior, possession of evil supernatural powers were sequel to such conditions. The respondents stated that the community becomes frightened of such children because they possess powers to pronounce curses on people. This will definitely lead to avoidance of these children, social isolation, untold stigmatization and ostracization of such children. This may result in a bleak future for them as this may affect future pursuits such as social relationships, employment and even pursuit in marriage in the future. It has been documented that the stigmatized are often ostracized, rejected, scorned and shunned [23]. They often experience psychological distress, view themselves disdainfully and this may take a toll on self-esteem, scholastic achievement [23]. The corresponding author has had to intervene in two different instances whereby the mothers of such children were to be sent packing out of their matrimonial homes by their mothers in law if they did not get these teeth extracted.

Of interest is that quite a number (33.7\%) TBA's would recommend extraction of these teeth with/or without sacrifices which may be harmful to the child. It is believed that the sacrifices will result in spiritual cleansing of the child and the family. However, such treatment is done in unhygienic conditions which expose the child to unnecessary pain, bacterial infection, Human Immuno Virus infection, hepatitis Binfection and tetanus. Even though the usual line of management is to counsel the parents and leave the teeth alone, with regards to a transcultural approach it has been suggested that a dentist in a community similar to that reported in this study should comply with the parents wish if they state they cannot bear the societal pressure and have the offending tooth extracted [6]. This will at least save the child from the untold life long hardship of being stigmatized and suffering reproach. It is worthy of note that from per- sonal observation in this environment, patients in which the dentist denied extraction had the teeth forcefully removed by quacks and local herbalists. Denloye and Osuh [7] have reported cases whereby counseling sessions were held for affected parents who became lost to follow up and later appeared with the babies having the upper primary central incisors missing.

\section{CONCLUSIONS}

Over half of the TBA's have seen a baby cut the deciduous upper central incisors first. Majority of the TBA's have erroneous beliefs on the causes and management of situations involving children who have erupted the maxillary deciduous incisors ahead of the mandibulars. Many of the TBA's have dissenting mind- 
sets towards such children and their families. The practices of many of the TBA's towards such teeth are disturbing and necessitate urgent intervention. The risks are that wrong advice may be given to such parents by the TBA's and affected children may be deserted, abandoned, stigmatized and exposed to hazards. Older and less educated TBA's have a greater tendency to believe these misconceptions.

\section{Recommendation}

TBA's play an important role in the society (particularly in developing nations) and giving them health education to change their wrong beliefs will have an impact in the society. It should be targeted particularly at the older and the less educated TBA's. Also there should be health enlightenment campaigns at various antenatal clinics and well baby infant clinics.

\section{REFERENCES}

[1] Pahkala, R., Pahkala, A. and Laine, T. (1991) Eruption pattern of permanent teeth in a rural community in northeastern Finland. Acta Odontologica Scadinavica, 49, 341349.

[2] Gupta, A., Hiremath, S.S., Singh, S.K., Poudyal, S., Niraula, S.R., Baral, D.D. and Singh, R.K. (2007) Emergence of primary teeth in children of Sunsari District of Eastern Nepal. McGill Journal of Medicine, 10, 11-15.

[3] Choi, N.K. and Yang, K.H. (2001) A study on the eruption timing of primary teeth in Korean children. Journal of Dentistry for Children, 68, 244-249, 228.

[4] Guna Shekhar, M. and Tenny, J. (2010) Longitudinal study of age and order of eruption of primary teeth in Indian children. Journal of Clinical and Experimental Dentistry, 2, e113-e116.

[5] Avery, J.K., Steele, P.F. and Avery, I. (2002) Oral development and histology. 3rd Edition, Thieme Medical Publishers, New York, 132.

[6] Aderinokun, G.A. and Oyejide, C.O. (1991) Societal opinions on the eruption of deciduous maxillary central incisors before the mandibular ones in Nigeria. African Dental Journal, 5, 26-30.

[7] Denloye, O. and Osuh, M. (2011) Parental attitude to reversal of eruption sequence in Nigeria. 23rd Congress of the International Association of Paediatric Dentistry, 15-18 June 2011, Athens, 153.

[8] World Health Organization (2010) Classifying health workers. Geneva.

http://www.who.int/hrh/statistics/Health workers classifi cation.pdf

[9] Brennan, M. (1989) Training traditional birth attendants. Postgraduate Doctor, 11, 16-18.

[10] Campero, C., Garcia, Diaz, C., Ortiz, O., Reynoso, S. and Langer, A. (1998) “Alone, I wouldn't have known what to do": A qualitative study on social support during labor and delivery in Mexico. Social Science and Medicine, 47, 395-403.

[11] Mathews, M.K., Walley, R.L., Ward, A., Akaidem, M., Williams, P. and Umoh, H. (1985) Training traditional birth attendants in Nigeria-The pictorial method. World Health Forum, 16, 409-413.

[12] National Population Commission Oyo State (2006) Census.

[13] Oyo State Human Resources for Health Index (2010) Department of Planning Research and Statistics. Ministry of Health, Oyo State.

[14] Mary Slessor. http://en.wikipedia.org/wiki/Mary_Slessor

[15] Hill, C.M. and Ball, H.L. (1996) Abnormal births and other "ill omens". The adaptive case for infanticide. $\mathrm{Hu}$ man Nature, 7, 381-401.

[16] Sargent, C.F. (1989) Maternity, medicine, and power: Reproductive decisions in urban Benin. 2nd Edition, University of California Press, Berkeley, 25-40.

[17] Mingi. http://www.en.wikipedia.org/wiki/Mingi

[18] Uchegbue, C.O. (2010) Infancy Rites among the Igbo of Nigeria. Research Journal of Internatıonal Studies, 17, 159-164.

[19] Kipkorir, B.E. and Welbourn, F.B. (2008) The Marakwet of Kenya: A preliminary study. 2nd Edition, East African Educational Publishers, Nairobi, 50.

[20] Bhatt, S.C. and Bhargava, G.K. (2006) Land and people of Indian states and union territories-Punjab. 1st Edition, Kalpaz Publications, Delhi, 322.

[21] Dosanjh, J.S. and Ghuman, P.A.S. (1996) Child-rearing in ethnic minorities. 1st Edition, Multilingual Matters, Clevedon, 61 .

[22] Fennell, C.W., Lindsey, K.L., McGaw, L.J., Sprag, S.G., Stafford, G.I., Elgoraschi, E.E., Grace, O.M. and van Staden, J. (2004) Assessing African medicinal plants for efficacy and safety: Pharmacological screening and toxicity. Journal of Ethnopharmacology, 94, 205-217.

[23] Heatherton, T.F., Kleck, R.E., Hebl, M.R. and Hull, J.G. (2000) The social psychology of stigma. 1st Edition, Guilford Press, New York, 153-243. 